This item was submitted to Loughborough's Research Repository by the author.

Items in Figshare are protected by copyright, with all rights reserved, unless otherwise indicated.

\title{
Strategy content and public service provider performance in the UK: an alternative approach
}

PLEASE CITE THE PUBLISHED VERSION

http://dx.doi.org/10.1111/padm.12090

PUBLISHER

(c) John Wiley and Sons Ltd

VERSION

AM (Accepted Manuscript)

LICENCE

CC BY-NC-ND 4.0

\section{REPOSITORY RECORD}

Hodgkinson, lan R., and Paul Hughes. 2019. "Strategy Content and Public Service Provider Performance in the UK: An Alternative Approach”. figshare. https://hdl.handle.net/2134/14765. 
This item was submitted to Loughborough's Institutional Repository (https://dspace.lboro.ac.uk/) by the author and is made available under the following Creative Commons Licence conditions.

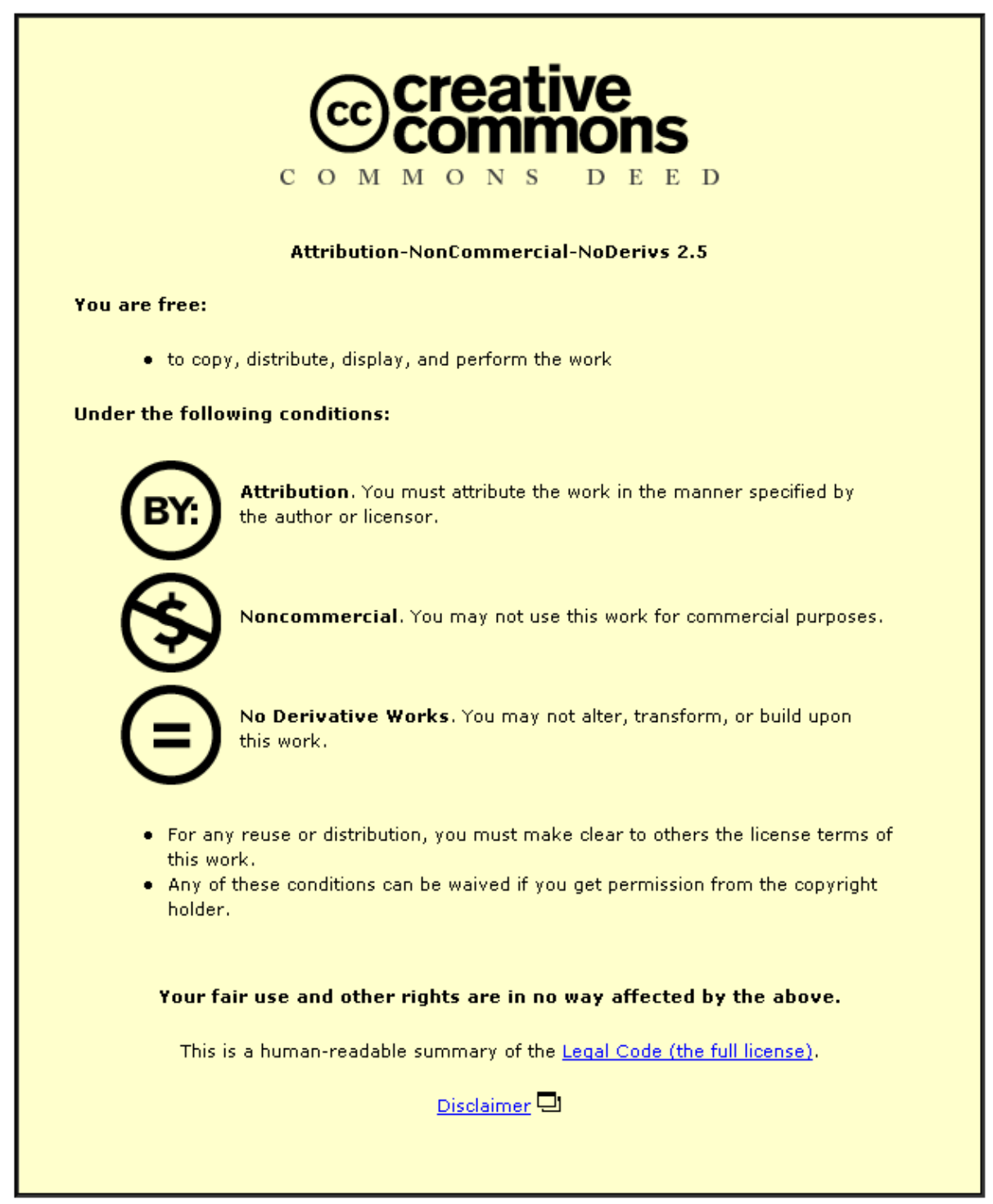

For the full text of this licence, please go to: http://creativecommons.org/licenses/by-nc-nd/2.5/ 


\title{
STRATEGY CONTENT AND PUBLIC SERVICE PROVIDER PERFORMANCE IN THE UK: AN ALTERNATIVE APPROACH
}

\author{
Public Administration
}

\author{
IAN R. HODGKINSON ${ }^{1}$ \\ The School of Business and Economics, Loughborough University, Loughborough, United \\ Kingdom.
}

\section{PAUL HUGHES ${ }^{2}$}

The Business School, Durham University, Durham, United Kingdom.

${ }^{1}$ Loughborough University, School of Business and Economics, Loughborough, Leicestershire LE11 3TU, United Kingdom. Tel: +44 (0)1509 223865. Email: I.R.Hodgkinson@lboro.ac.uk.

${ }^{2}$ Durham University, Business School, Ushaw College, Durham DH7 9RH, United Kingdom. Tel: +44 (0) 19133 45393. Email: Paul.Hughes@durham.ac.uk.

This article presents an alternative empirical test of the relationship between strategy content and service provider performance. Strategy content, conceptualized as comprising strategic stance and strategic action, has been shown to be a means to improve public service performance. We contribute to this growing body of research by deriving an alternative typology of strategy to better reflect competitive conditions in the public sector, which existing strategy typologies cannot fully explain. By assuming the view that public service providers must follow strategies best suited to their internal and external conditions for improved performance, we evaluate the significance of 'fit' between alternative strategic stances and organizational characteristics. Compromising the delivery of a strategy invariably leads to a misfit between strategy and what the service provider is actually doing. We highlight how to optimize strategic fit, to maximize service provider performance. Conclusions are drawn for public management theory and practice. 


\section{INTRODUCTION}

In an environment in which public management reforms emphasize the value of a comprehensive approach to strategy, a core managerial function is to shape strategy content, that is, how an organization interacts with its environment, and the way it seeks to improve performance (Andrews et al. 2009). The idea that strategy content influences performance is central to generic management theory (Meier et al. 2007) and implies that managers can make a major difference in service standards through the strategies they follow (Andrews et al. 2006). Boyne and Walker (2004) conceptualize strategy content in the public sector at two levels. First, strategic stance is the broad way in which an organization seeks to improve its performance. Second, strategic actions are the specific steps that an organization takes to operationalize its stance, referring to how organizations actually behave, rather than their intended approach (Andrews et al. 2006).

The contention that strategy content is a means to improve public service provider performance is increasingly supported (e.g. Andrews et al. 2006, 2009; Meier et al. 2007, 2010; Walker et al. 2010). However, these examples are based on the application of the Miles and Snow (1978) typology. The absence of evidence assessing the appropriateness of alternative strategic management models associated with the private sector has arisen from a lack of attention from public administration academics, with many being critical of the movement toward the adoption of private sector practices. With reforms introducing private-sector management practices into key areas of service provision (Liu et al. 2008) it is timely to consider the contribution of alternative strategic management models to service provider performance.

As outlined by Vining (2011), public management research and practice could draw more extensively on generic management and organization theory knowledge. In extending this 
research, we investigate the relationship between strategy content and service provider performance in two important ways. Firstly, it is inappropriate to categorize service providers as belonging solely to a single strategic stance (Boyne and Walker 2004; Meier et al. 2010) and we expect strategies to reflect a combination of strategy dimensions. From public leisure sector data, we derive an alternative typology of strategic stance comprising strategy dimensions drawn from Porter’s (1985) and Faulkner and Bowman’s (1995) strategy typologies. Secondly, we follow strategic fit theory: to maximize performance, service providers must follow strategies best suited to their internal and external conditions. Strategic fit is achievable by aligning internal strategic resources with external environmental opportunities and threats through a market orientation (Hughes and Morgan 2008). The relevance of market orientation and resource-based theories to the public sector has been evidenced in the public administration literature (e.g. Bryson et al. 2007; Walker et al. 2011). While the two streams of research form relatively independent literatures (the former emphasizing the need to base strategy on external, market considerations and the latter on internal, organizational resources and capabilities), these two approaches can be reconciled through the concept of strategic fit. Indeed, authors such as Andrews et al. (2009, p. 747) state that it will be essential to evaluate 'whether public organizations that achieve the tightest fit between strategies and organizational characteristics are also the highest performers'. Our research is a step in this direction.

This study contributes to public administration theory in two important ways. First, and to the best of our knowledge, this is the first study to empirically derive an alternative typology of strategic stance for the public sector while accounting for performance implications. Accordingly, the study contributes new evidence to expand the relevance of alternative strategic management models to public service management. Second, and to the best of our knowledge, 
this is the first study to test empirically the role of market orientation and strategic resources concurrently in relation to fit with stance. In doing so, we can determine the extent to which different strategies rely on market orientation and strategic resources. We also contribute to public service practice as providers can use our research to determine the optimum strategy for their respective strategic resource endowments and degree of market orientation.

In the first part of this article we review strategy content (stance and actions), considering the limitations of its conceptualization and derive a series of research propositions for the public leisure sector (e.g. public indoor sports and recreation facilities that are managed between public, private, and nonprofit domains). In the second part of this article we outline our research methods and interpret our findings. We then evaluate the significance of fit between strategies and organizational characteristics for service provider performance.

\section{STRATEGIC STANCE}

Stance is depicted in strategic management through the use of typologies. The two dominant typologies in the private sector were developed by Miles and Snow (1978) and Porter (1985). Research in the public sector has typically adapted the former, examining the central components of the Miles and Snow typology (Prospector-Defender-Reactor) (e.g. Andrews et al. 2006, 2009; Meier et al. 2007, 2010; Walker et al. 2010). These studies have developed and tested hypotheses that different strategic stances have different effects across public services (Boyne and Walker 2010). In doing so, these examples have extended the broad but mixed support for the Miles and Snow model of strategy and performance from the private to the public sector. 
However, DeSarbo et al. (2005, p. 51) suggest that since the Miles and Snow stances were originally developed for a small number of industries, they may not sufficiently capture the strategies that exist in other industry settings:

A business will select a particular strategic type based on its particular internal strengths (capabilities) and external (environment) circumstances, and the strategic types that are actually employed may not, in fact, be cleanly interpretable as the four Miles and Snow (1978) categories.

In accounting for divergent findings on this typology across different empirical contexts, Walker et al. (2010) suggest that the optimal strategy may depend on organizational type and organizational context. Therefore alternative strategy typologies may be more appropriate for different public service contexts depending on the internal and external conditions present.

\section{Alternative typologies}

Porter (1985) argued that in order to achieve competitive advantage the firm must adopt one of three generic strategies: cost leadership, differentiation, and focus. Organizations that are 'cost leaders’ become the lowest-cost organization in a domain of activity; ‘Differentiation’ involves uniqueness along some dimension that is sufficiently valued by customers to allow a price premium; and, 'Focus' emphasizes the differences between a focuser's target segments and other segments in the industry (e.g. cost focus exploits differences in cost behaviour in some segments). The competitive orientation of Porter's typology is often deemed inapplicable to public sector settings (Andrews et al. 2012) despite cost being a prevalent feature of competition in the public context (Johanson 2009), where competitiveness can mean:

the ability to provide a service comparable to alternative providers at lower cost (although the provider may choose to retain a higher price) or the ability to provide superior service at 
comparable cost (although the provider usually sets a higher price). (Benson and Henderson 2005, p. 257)

However, as Johnson et al. (2008) note, too often managers conceive of generic strategies in terms that are internal to the organization which are of no value in achieving organizational performance unless they are of value to the customer, beyond those of competitors.

Faulkner and Bowman’s (1995) strategy typology is more market-focused, emphasizing perceived value and price for customers rather than costs to the organization. This is consistent with increasing emphasis on customer focus and customer choice in UK public services (Walker et al. 2011). Here, customers may choose to purchase from one source over another because either the price is lower than that of another firm, or the market offering is more highly valued by the customer (Johnson et al. 2008). This typology presents three identifiable zones of feasible strategies: the 'low-price zone’ accommodates different combinations of low prices and low perceived value; the 'differentiation zone' builds on high perceptions of service benefits among customers (with or without a price premium); and, the 'hybrid strategy zone' involves lower prices than differentiation strategies, and higher benefits than low-price strategies (Johnson et al. 2008). The hybrid strategy zone challenges the assumption that each organization has only a single strategic stance. Indeed, 'Mintzberg argues that Porter provides a menu of strategies that are potential complements rather than stark alternatives’ (Boyne and Walker 2004, p. 233). This suggests that an optimal stance may be a combination of these strategy dimensions.

Hodgkinson (2013) highlights associations between the above strategies and public leisure service performance, but acknowledges that public organizations are likely to vary in the extent to which they prioritize different strategies. Similarly, in assessing the application of Miles and Snow's model of strategy, Boyne and Walker (2004) suggest that a mix of strategies is 
likely to be pursued at the same time, such that organizations are likely to be part prospector, part defender, and part reactor (Andrews et al. 2006). This highlights a limitation of strategy research in the public sector. Though it has been identified that stance is a blend of strategy dimensions, existing classifications of strategy are not designed to capture this. For example, Miles and Snow (1978) stressed that the various strategic types would perform equally well in any industry, while Porter (1985) argued that the competitive generic strategies are mutually exclusive. Therefore, to better reflect the multi-dimensional nature of strategic stance and to extend strategy research in the sector, stance needs to be conceptualized as a continuum beyond the singular categorizations of pre-existing typologies (Boyne and Walker 2010).

\section{Suitability of alternative typologies to the public sector}

A large range of public sector services have been subjected to market forces, both in the UK and the US, through competition and externalization (e.g. social services, waste management, culture and leisure services, public transit agencies, public housing and redevelopment agencies, and county medical centres) (Boschken 2000; Brewer and Walker 2010). The increasing prominence of external agencies entering the public sector to capitalize on opportunities in service delivery has resulted in highly competitive market environments (Boschken 2000; Walker et al. 2011). Public agencies embroiled in market processes must develop strategies that allow them to compete and succeed (Walker et al. 2011). For example, under the conditions of market supply and demand, consumer preferences are fundamental considerations in judging the quality and availability of service providers, thus an external orientation is necessary to focus on an organization's responsiveness to the demands of its customers (Obeng and Ugboro 2008). Viable strategies for public agencies in competitive markets will differ greatly to those in other markets, where there is no consumer choice provided by substitutes or where a monopoly exists. 
Application of alternative strategy typologies to public agencies has typically been opposed due to the perceived differences between the goals of public and private sector organizations (Vining 2011). However, public agencies that operate in competitive settings are suggested to behave more like private firms seeking their own competitive edge (Boschken 2000). This implies that public organizations will perform better if they behave like private organizations in competitive markets, competing with rivals to meet consumer demands (see Walker et al. 2011). For example, business techniques of performance management and key performance indicators are used in public leisure provision to maximize output, encouraging a 'business-like' approach and responsiveness to customer needs (Houlihan and Green 2009). The leisure sector is an appropriate context to examine the contribution of alternative strategic management models. Leisure providers are indicative of public agencies operating in market conditions where there is competition to deliver services that meet the actual requirements of the customer, which is integral to competitiveness in the sector.

\section{STRATEGIC ACTION}

The second dimension of strategy content is based on the types of action used to operationalize stance; according to Boyne and Walker (2004) these include changes in markets, services, revenues, the external organization, and the internal organization; though service providers have limited choices to change the first three. This study focuses on the organization-level, since (a) providers have direct control over internal organization-level conditions and (b) very little research has been conducted on the links between strategies and organizational characteristics (Boyne and Walker 2004). A number of studies by Andrews et al. have sought to address this 
knowledge gap by accounting for management reform (2006); distinctive organizational structures and processes for strategy types (2009); organizational implementation styles (2011); and, the implications of internal alignment of management and organization (2012). We contribute to this growing body of research by evaluating the significance of 'fit' between alternative strategic stances and organizational characteristics to better reflect competitive conditions in the sector, which existing strategy typologies cannot fully explain.

Miles and Snow (1978) imply that the firm's strategic type shapes its capabilities (i.e. prospectors keep on prospecting), but the relationship is more complex than this (DeSarbo et al. 2005). Strategy research suggests that the suitability of a strategy (i.e. the right strategy to pursue) is definable in terms of its fit with organizational and environmental contingencies (Hughes and Morgan 2008). This fit is achieved by aligning the organization's strategic resources with the environment, through strategy, building on the notion that strategy needs to fit with organizational characteristics and the external environment to achieve better outcomes (Meier et al. 2010). Fit, then, can be facilitated through market orientation and the creation and deployment of resources as outlined by resource based theories.

\section{Market orientation}

Market orientation emphasizes an external focus on customers and competitors (Walker et al. 2011). Research has suggested that organizations with (1) high calibre, organization-wide generation of market intelligence pertaining to current and future customer needs; (2) sharing and dissemination of that intelligence across the organization; and, (3) organization-wide responsiveness to those market needs, perform better in the market-place: 
Intelligence generation: Market orientation depends on organizations having processes for effectively collecting market intelligence about customers and competitors. The intelligence generated helps inform the organization to develop responses (Kohli and Jaworski 1990);

Intelligence dissemination: Mechanisms must be in place for intelligence generated to be disseminated effectively to other parts of an organization (Kohli and Jaworski 1990). Intelligence dissemination refers to the process and extent of market information exchange within a given organization (Kohli et al. 1993);

Responsiveness: Market intelligence can increase the scope, accuracy, and relevance of response to current market conditions. The speed and coordination with which market intelligence is responded to dictates whether the organization responds faster than competitors and in a manner timelier to its customers (Kohli et al. 1993).

Market orientation is appropriate for public service agencies as its application is driven by the objectives being pursued, the need to attract customers and fending off rival providers, whether in a business or public context. This reflects policy discussion which emphasizes customer satisfaction and customer choice, representing a more business-like approach to managing public services (Walker et al. 2011). Market orientation has been highlighted as essential to service performance, demonstrated by Liu et al. (2008, p. 190) who state:

[S]uccess will only come to the organization that best determines the perceptions, needs and wants of target markets and satisfies them through the design, communication, pricing and delivery of appropriate and competitively viable offerings.

To compete in a market, a public organization has to systematically collect evidence on that market (Walker et al. 2011). Market orientation reflects such a capability, comprising 
behavioural characteristics that enable the organization to operate more effectively in that market. Typically, market orientation is idiosyncratic to the organization and involves a complex interplay with other resources, which are all important factors in creating performance returns (Hooley and Greenley 2005). Moreover, Boyne (2006) argues that a lack of strategic fit with the external environment is an important reason for strategic failures in public organizations. However, though market orientation can strategically align an organization with its external environment, internal resource considerations are also necessary.

\section{Strategic resources}

Johanson (2009) contends that the success of public organizations cannot be found directly from their adaptation to the environment but in the unique resource combinations of the organization. Central to this view is the idea that public organizations possess heterogeneous resources and capabilities that can provide a basis for sustained performance (Bryson et al. 2007). However, purely possessing a valuable resource alone does not allow for performance gains; rather, only when deployed through strategy do resources provide the potential for enhanced performance (Hunt 2000). To achieve superior performance relative to competition organizations must use bundles of resources which are hard for competitors to imitate or acquire. The implication of intangible resources being heterogeneous and imperfectly mobile is the potential this provides for creating value and achieving competitive advantage, hence they may be referred to as strategic (Hughes and Morgan 2007). Examples of strategic resources include various forms of human (e.g. employee skills, learning, commitment, and training), informational (e.g. knowledge, understanding of markets, and customers), relational (e.g. relationships, alliances, and cooperative agreements), and organizational (e.g. culture, firm resources, and capabilities) dimensions (Hunt 2000). When a comparative advantage in strategic resources is exhibited, this 
should lead to improved performance (Hodgkinson and Hughes 2012). In applying this to strategic fit theory, any strategy adopted must match the available strategic resources of the service provider. If not, then it is unlikely that the provider is maximizing its performance potential.

Whilst there are numerous resources and capabilities that represent human, informational, relational, and organizational dimensions, it would be impractical to consider all of these when examining strategic resources. However, elements may be drawn reflecting these dimensions. The five elements examined-strategy commitment, implementation support, implementation effectiveness, organizational learning and training-directly map on to these dimensions and are discussed in the literature as key strategic resources (Hunt 2000; Hughes and Morgan 2007):

Strategy commitment: The extent to which a manager comprehends and supports the goals and objectives of the chosen strategy (Noble and Mokwa 1999). Developing commitment to strategy builds support for the strategy, provides impetus to its development, and limits resistance to it;

Implementation support: Refers to the resource structure of the organization being aligned to the chosen strategy and the subsequent allocation of necessary resources for the successful realization of strategy (Hughes and Morgan 2007);

Implementation effectiveness: The ability to implement effectively is a strategic resource, which is developed over time from the skills and accumulated knowledge of the organization, enabling it to make use of its assets to achieve desired goals (Noble and Mokwa 1999);

Organizational learning: Organizations learn from operating in their respective marketplaces while competing; the development of new knowledge or insights provides a means to improve resource deployment and, as a consequence, service provision (Hunt 2000); 
Training: A planned process to modify attitudes, knowledge and/or skill behaviour through learning experience. Training is a means to develop depth in selected human skills to achieve sustainable advantages (Snell and Dean 1992).

Strategic resources and management's ability to marshal these are fundamental to achieving service goals. However, resources can only be considered valuable when positioned in the external environment. Hence, strategy requires fit between the external environment and strategic resources. For resources to be leveraged for performance gains requires their application in the market (market orientation); while, simultaneously recognizing that if that application is to be sustainable in the face of competition, then strategy must be built on distinctive resources and capabilities (strategic resources) (Hooley and Greenley 2005).

\section{RESEARCH PROPOSITIONS}

Strategy does not inevitably neatly fall into the tight groupings prescribed by pre-existing typologies (e.g. Miles and Snow 1978; Porter 1985). Rather, fit theory implies that organizations adopt strategies that are best suited to their internal and external conditions. Accordingly, strategy can reflect multiple dimensions beyond singular categorizations forced upon them by these pre-existing typologies. We develop a new typology of stance derived from different dimensions of Porter's and Faulkner and Bowman's strategy typologies, and conceptualize this as a continuum along which the strategies of public leisure providers are positioned (i.e. all strategies in the public leisure sector are a combination of different dimensions of low-cost, value-added, cost-focus, low-price, and hybrid stances). By empirically deriving an alternative strategy typology we intend to capture competitive market conditions in the public sector. 
Moreover, we suggest that strategic actions (market orientation and strategic resources) interrelate with strategic stance such that the performance of strategy is dependent on the fit between stance and organizational characteristics.

The analysis does not begin with any a priori expectations about the number of strategies that will be derived, nor concerning the actions that underpin them, nor in how they differ. But, we suggest that a) strategic stance will be a unique combination of each underlying dimension of strategy; b), each stance will comprise a unique combination of strategic actions; and, c) each identified strategy will have different service provider performance outcomes.

\section{METHODOLOGY}

\section{Data generation}

Using a mail survey approach, this study targeted 1060 public leisure providers in England and a $26 \%$ response rate was achieved. A public leisure provider, for the purposes of this study, refers to a publicly-owned site with at least one of the following facilities: health and fitness suite, swimming pool, or sports hall, where at least one is available to members of the general public on a pay and play or membership basis. Facility-level managers were deemed key informants consistent with extant research examining the strategic characteristics of service providers (Benson and Henderson 2005). To protect against common method variance (CMV) biasing our data, in developing the questionnaire, the directions of Spector and Brannick (1995) were followed: measurement scales were placed in random order; non-idealized responses and wording neutrality were adopted; questionnaire length was short (three pages); and detailed instructions for completion were provided. 
Non-response bias was examined by performing a respondent-non-respondent comparison on a random sample of 100 respondents and 100 non-respondents. We examined for significant differences between these public service providers using objective data on adult membership numbers and 'pay \& play’ cost. No significant differences were found between respondents and non-respondents for adult membership ( $\mathrm{F}=0.129$; ns) and 'pay \& play' cost ( $\mathrm{F}$ $=2.126$; ns). Thus, we conclude our sample is representative of the population at large.

\section{Measures}

Appendix A provides details of the wording of all measure items, their reliability statistics and the factor loading and associated t-values in confirmatory factor analysis (CFA). All constructs exhibit acceptable reliability.

\section{Performance}

Service provider performance has two components: business performance and customer performance. Business performance is a necessity for public service providers to ensure they have sufficient revenues to maintain or expand services (Andrews et al. 2006). Four business performance items were adapted from Delaney and Huselid (1996). The items place emphasis specifically on new customer sales, profitability, market share, and marketing (the ability to refine organization activities now and into the future to sustain superior performance). Customer performance is representative of the need to provide services that meet the expectations of citizens (Boyne and Walker 2010). Four customer performance measures comprising: customer satisfaction, customer value, quality of services, and development of services, were adapted from Krohmer et al. (2002) and Delaney and Huselid (1996). Together these variables provide a broad assessment of performance from a service provider perspective. 


\section{Strategic stance and action}

Single-item measures were used for strategic stance. Low cost was operationalized through a measure of cost minimisation. A cost-focus stance was operationalized through low price while maintaining low operating costs to target provision toward price-sensitive niches. Providers with a value-added approach were expected to differentiate their offerings and charge a price higher than the average. Price-based stance was operationalized through a measure of low price while maintaining similar service benefits to rivals. A hybrid stance was operationalized by asking informants whether the service delivered greater benefits to customers together with low prices.

Multiple-item measures were used for strategic action. Market orientation measures were matched to the categories of intelligence generation, intelligence dissemination, and responsiveness. Items were identified for each from Kohli et al. (1993) and Vázquez et al. (2002). Strategic resources were operationalized as strategy commitment, implementation support and effectiveness, learning, and training. Measures of implementation effectiveness and commitment were adapted from similar items used by Noble and Mokwa (1999). Implementation support and learning were captured by adapting pre-existing measures used by Hughes and Morgan (2007). Measures of training were adapted from similar items used by Snell and Dean (1992) and Delaney and Huselid (1996). Each facet of strategy content was assessed by using attitude statements where responses were measured on a seven-point, likert-type scale ranging from strongly disagree (1) to strongly agree (7).

\section{Common method variance}

As we rely on subjective data we tested for CMV using a marker variable test. First, following Lindell and Whitney (2001), we included a marker variable ('taking criticism of the service 
facility personally') which is theoretically unrelated to the constructs in our model. The correlations of this item with our study variables were insignificant $(-.02<\mathrm{b}<.10, \mathrm{p}>.10)$. This implies that respondents did not merely 'tick boxes' sequentially and did seek to answer the questions with thought. Second, following the guidance of Malhotra et al. (2006) we used this marker variable to examine for CMV within a CFA of the measures. As we use maximum likelihood estimation using the covariance matrix in LISREL 8.8, we differ from Malhotra et al. (2006) by examining how covariance (and not correlation) between variables is affected by CMV. We calculated average covariance (Malhotra et al. 2006) as $\mathrm{r}_{\mathrm{m}}=0.21828$. A CMVadjusted covariance matrix was then calculated. This matrix was then used by re-specifying the original CFA model. The original CFA model results were: $\chi^{2}$ (d.f.) $=750.43(419) ; \mathrm{p}=.00$; $\chi^{2} /$ d.f. $=1.79 ; \mathrm{RMSEA}=.055 ; \mathrm{GFI}=.85 ; \mathrm{CFI}=.97$. The CMV-adjusted CFA model results were: $\chi^{2}$ (d.f. $)=760.00(419) ; \mathrm{p}=.00 ; \chi^{2} /$ d.f. $=1.81$; RMSEA $=.055$; GFI $=.85$; CFI $=.95$. The results show that after adjusting the covariance matrix to account for CMV, the changes in the CFA model are not of significance and did not materially affect model fit. Thus, CMV bias does not appear a threat but we recognize that these tests cannot fully eliminate the potential for bias.

\section{DATA ANALYSIS}

Though the strategy literature has identified potential strategic stances, it does not necessarily mean that providers will strictly follow one type or indeed that such strategic stances transfer across different contexts. By using cluster analysis, we can identify latent patterns or strategic stances that may not otherwise be identifiable or apparent through observation or some other statistical analysis (Hughes and Morgan 2007). Cluster analysis is valuable in strategy research 
due to its ability to classify a large number of observations across multiple variables (Ketchen and Shook 1996). Cluster analysis enables researchers and managers to take a sample of public service providers and identify clusters, or groups, among them where the identified clusters are internally similar but exhibit inter-group differences (Hughes and Morgan 2007). Further statistical analysis can subsequently be performed on the identified groups to determine why or how these groups are statistically different to one another. Accordingly, cluster analysis can provide rich descriptions of clusters, or groups, as it can handle multiple variables in defining them and does so without over specifying the model (Ketchen and Shook 1996), which may lead to statistical errors. This enables researchers to develop rich descriptions and insights into the groups and derive meaningful reasons for differences between them, which can then serve as useful advice and guidance to managers and practitioners alike.

To identify the possible strategies of the service providers in our sample, we first need to specify criteria that provide a basis for this (Ketchen and Shook 1996). In our survey, we sought information on these by asking respondents to rate the degree to which their strategy reflected various strategic stances. If we follow Porterian views of strategy, then we would expect respondents to clearly follow one particular stance, but, we expect service providers to follow a strategic approach that combines two or more stances such that distinct clusters or types of strategy can be identified for groups of providers in the sample. Strategic stances were described as statements in the questionnaire and respondents were asked to rate the degree to which their strategy reflected these statements. Here we noted the advice of Ketchen and Shook (1996) by ensuring all statements were measured with a standard scale. They comment that derived clusters may be skewed or biased if subsets of variables used in the clustering process have much larger measurement ranges. For instance, five variables measured along 7-point Likert-type scales and 
another five variables measured with scales ranging from 0 to 100. If clustering variables are measured in non-standard ways then items having longer or larger measure ranges will be dominant in the clustering process. This can then lead to biased clusters being identified as that subset of variables will dominate the definition of the derived clusters (Ketchen and Shook 1996).

Clustering was performed through a two-stage process using SPSS Statistics 19 and following the prescriptions of Ketchen and Shook (1996), Saunders (1999), Hooley and Greenley (2005), and Hughes and Morgan (2007). First, we used hierarchical clustering as suggested by Ketchen and Shook (1996) and Saunders (1999) but employed Ward’s (1963) hierarchical method to identify groups of providers that exhibited similar strategic properties; due to its consistency in recovering data, ability to generate compact spherical clusters, and lack of distinct and explicit outliers in the data (Ketchen and Shook 1996; Hughes and Morgan 2007). Ward's (1963) method suggested two possible solutions, a four-cluster and a three-cluster arrangement. Following best practice (e.g. Ketchen and Shook 1996; Hughes and Morgan 2007), we examined scree diagrams and the dendogram and then assessed the agglomeration statistics provided and concluded that the four-cluster solution appeared optimal and provided the best fit for the data. Second, we moved to clustering using the K-means method as recommended by Saunders (1999) and Hooley and Greenley (2005). K-means clustering is a nonhierarchical clustering method and makes multiple passes through the dataset to allow each observation to change cluster membership based on their distance from the recomputed centroids (Ketchen and Shook 1996). This method is useful as the final clustering solution maximizes within-cluster similarities and between-cluster differences. It is important to combine the use of hierarchical (Ward) and nonhierarchical (K-means) clustering methods so as to triangulate the results and establish cluster reliability and validity (Ketchen and Shook 1996). This method once again revealed a 
stable four-cluster solution that provided clearly interpretable results, were statistically distinct, and crucially, were strategically distinct. The clusters identified in both approaches were directly similar and comparable and as this generated similar results to Ward's (1963) method, the cluster solution demonstrates reliability. Thus it was decided that this four-cluster solution was indeed the optimal solution. The strategy clusters identified were assessed for appropriate descriptors and labelled accordingly. Table 1 provides information on the clusters identified.

[Table 1 here]

\section{RESULTS}

Firms in Cluster 1 are described as chaotic $(n=54)$. These service providers emphasize no specific strategy dimensions and rather appear confused as to what they are truly seeking to achieve and how they are attempting to go about it. Service providers captured in Cluster 2 are termed value differentiators $(\mathrm{n}=62)$; these providers tailor their offers to different societal groups with a focus on delivering high customer value. Service providers in Cluster 3 constitute the largest grouping $(\mathrm{n}=102)$ and are labelled as following an equilibrial strategy. In essence, these service providers seek to address the needs of all citizens, simultaneously emphasizing a hybrid approach of a low price strategy and focus on superior service value. In doing so, they seek to maintain an equilibrium between offering superior service by balancing costs and prices for affordability (from both a customer and business perspective). The final cluster are defined as socially responsible $(n=61)$ emphasizing a cost-focus approach coupled with a low price strategy, which simultaneously requires a low-cost base. All clusters are clearly strategically 
distinct and confirm that public service providers follow more complex strategic approaches than have been currently identified or examined in extant literature.

We proceeded to conduct a discriminant analysis on the four-cluster solution following the recommendations of Saunders (1999). This resulted in three discriminant functions (Table 2) and illustrates the distinctions between the cluster centroids. In noting that the cluster centroids discriminate between each other and classification tests revealed $98 \%$ of the original analysis group were correctly classified, we can be confident that the results once again demonstrate reliability and that the final four-cluster solution are distinct and meaningful.

[Table 2 here]

Multivariate analysis of variance was performed to test the null hypothesis that there are no simultaneous strategy group differences based upon the strategic action (strategic resources and market orientation) and performance variables. This null hypothesis is rejected. Significant differences were computed between the four groups along dimensions of strategic action (Wilks' lambda $=.76 ; F=3.56 ; p \leq .001)$ and performance (Wilks' lambda $=.86 ; F=7.28 ; p \leq .001$ ).

To identify significant differences between the groups on all of the strategic actions and performance dimensions, we proceeded to employ one-way analysis of variance with post hoc analysis using the Scheffé test. This is a post hoc test for comparing groups and identifying which comparisons among groups have statistically significant differences (Hughes and Morgan 2007). Tables 3 and 4 present the results.

[Table 3 here]

[Table 4 here] 
As regards dimensions of strategic action, service providers following chaotic and socially responsible strategies seem to (a) be endowed with lower levels of strategic resources relative to others and, (b) be worse at generating information and knowledge on markets and customers, and then disseminating and responding to that intelligence (see Appendix B for a summary of cluster characteristics'). In examining the Scheffé test results, the chaotic strategy would appear on balance to be the weakest strategic stance but on the flipside does provide an avenue for those providers less endowed with strategic resources and market orientation to compete. In terms of performance, the results once again present evidence that chaotic and socially responsible strategic stances are inferior and produce poorer performance outcomes when compared with value differentiation and equilibrial stances. In terms of achieving customer performance, a chaotic approach is the weakest and exhibits significant differences in comparison to both value differentiators and those following an equilibrial strategy. Anecdotally, value differentiation once again appears to provide the optimum strategic path. In terms of business performance, the results reflect those of customer performance but this time value differentiation exhibits statistically significant superiority to an equilibrial strategy. Furthermore, socially responsible strategies along with a chaotic strategy are substandard strategies for delivering superior performance relative to other strategic stances identified. Taken together, these results suggest that value differentiation is the best strategic stance for maximizing returns from strategic actions, but, is reliant on the service provider being endowed with both strategic resources and market orientation. The same can be said for an equilibrial approach as there are little in the way of significant differences between this approach and value differentiation except, and significantly so, when it comes to maximizing business performance. 


\section{DISCUSSION}

The chaotic stance appears to be weakest and bears similarities to Miles and Snow's reactor category. Though the absence of a substantive stance is suggested to afford reactors with greater responsiveness to the demands of the public sector environment, research suggests that a reactor stance is not a successful route to higher levels of service performance (Andrews et al. 2006, 2009; Meier et al. 2007). Though a chaotic stance appears to eschew deliberate strategy, much like reactors (Andrews et al. 2012), it still represents a route to performance gains (albeit the weakest). This stance, however, has a limited platform for significantly increasing performance, displaying the weakest endowments of strategic resources and marketing capabilities for strategy formation and implementation purposes. An inability to fit strategic resources and marketing capabilities with stance undermines the basis for stronger performance.

The lack of a clear approach and established routine for implementation distinguishes chaotic from an equilibrial stance, with the latter having a platform for significantly improving performance that does not apply, prima facie, to the chaotic stance. In particular, the equilibrial stance relies on learning and information distribution to provide a superior service while balancing costs and prices for affordability. This requires significant assimilation and dissemination of new market intelligence so as to both innovate and be able to meet the needs of numerous market segments simultaneously. By fitting strategic resources and marketing capabilities with strategy, these organizations are endowed with a basis for stronger performance.

Value differentiation represents the strongest stance reflecting similar findings presented by Andrews et al. (2006) where prospectors, organizations that respond to evolving trends in the marketplace through innovation (Meier et al. 2010), were the strongest performers. Based on the 
findings presented and existing research, the ability to deliver superior value in response to changing customer needs faster than competitors leads to greater performance returns relative to other stances; this appears to be particularly important under competitive market conditions (cf. Hodgkinson 2013). However, this approach demands the greatest endowments of strategic resources and market orientation (on balance) to achieve that performance potential. Value differentiators require high market orientation to continuously monitor evolving trends in the marketplace and for timely adjustments to be made to service provision. Strategy commitment is significant so as to minimize resistance to fast-paced change and to maintain a proactive stance to swiftly pursue value-adding opportunities.

Similar to defenders, a socially responsible stance aims to improve existing services in a secure niche, but is a weaker route to higher performance relative to value differentiation and equilibrial strategies. Nevertheless it is still more effective than a chaotic stance. This finding offers some support to research conducted in single purpose public organizations where focus on secure niches is associated with stronger performance (Meier et al. 2007; Andrews et al. 2009). Focusing efficiently on core tasks such as equity in provision through increased accessibility can therefore be a rational strategy (Meier et al. 2007). Organizations with this stance require strong information and knowledge on customers to improve the delivery of existing core activities, which in turn strengthens their position in narrow price-sensitive niches.

Existing studies have typically implied that the Miles and Snow 'analyzer' category is redundant because all organizations are prospectors and defenders to some extent (Andrews et al. 2009); analyzers represent a blend of strategies much like a hybrid strategy (low price and differentiation). These categorizations, however, neglect the complexity of strategy by failing to account for the numerous combinations of strategy dimensions that underpin strategic stance in 
the public sector. We have derived a new typology that goes beyond these singular categorizations. Each derived strategy is a unique blend of different dimensions of low-cost, value-added, cost-focus, low-price, and hybrid, and it is the degree to which these individual dimensions are emphasized (or not) within strategy that distinguishes the stances presented. This clearly separates our typology from existing strategy models in the public sector. Moreover, we point to the strategic resources and marketing capabilities needed to achieve selected stances.

Andrews et al. (2009) called for research to ascertain the importance of fit between strategies and organizational characteristics to performance. Our research is a step in this direction in establishing that (a) different strategies have different performance outcomes and (b) fit with the strategic resources and marketing capabilities of the provider is important as high performance cannot be achieved unless the provider has sufficient endowments consistent with the demands of the strategy pursued. Understanding this interrelationship between stance and action is important to managers as there are implications for performance. Managers need to account for strategic resource endowments and market orientation capabilities when developing strategy. Any compromise in delivering a strategy invariably leads to misfit between strategy and what the organization is actually doing; this will potentially lead to strategy failure and collapse of performance.

We recognize that the impact of different strategies on performance may also be contingent on wider institutional factors across public, private, and nonprofit domains, but this was beyond the scope of the study. Since the impact of stance may depend on the mix of public and private ownership, Boyne and Walker (2010) propose that future studies should consider the impact of publicness on the strategy-performance relationship between different types of institutions (i.e. public, private, and nonprofit). Further research is required to examine whether 
the identified relationships between the derived strategies and performance are contingent on institutional differences. By comparing public, private and nonprofit effects on these strategyperformance relationships, comparability across the publicness divide can then be explored.

Finally, the results are important from a strategic fit perspective. Managers of public service providers need to maximize use of their strategic resource endowments and market orientation capabilities in their strategy for better performance. In so doing, managers must choose and implement the most appropriate strategy. For example, those relatively well endowed with market orientation and strong on learning resources are well positioned to exploit an equilibrial strategy. Meanwhile those with similar market orientation capabilities but relatively lacking in strategic resources could be better served in following a socially responsible approach. Accordingly, the issue of strategic fit should be a prime consideration for managers in deciding on the best strategic stance to adopt and should not shy away from strategic change when it would clearly benefit performance vis-à-vis the results if an inappropriate strategy is followed when examined next to the relative endowments of the service provider.

\section{CONCLUSION}

In acknowledging the competitive market conditions under which some public organizations operate, we adapted strategy dimensions from Porter's and Faulkner and Bowman's typologies. Four distinct strategic stances emerged from the analysis. These did not, however, follow directly the generic strategies outlined in these typologies. Rather, they exhibited combinations of those strategies. This indicates that strategic stance in the public leisure sector is a complex combination of different strategy dimensions. As such, this research contributes a new typology 
of strategy to the field, derived specifically from public service providers, and we stress that researchers in this area must appreciate the multi-dimensional nature of strategy beyond the singular categorizations of pre-existing typologies in future research.

Three issues become apparent from our research. First, while we take an important step to assessing the importance of strategic resources and market orientation as actions required to effectively execute the new strategies that we have identified, there may be other characteristics at play that are significant. Second, we do not consider the implementation of these strategies beyond inferences regarding resource and marketing endowments. For instance, switching to an alternative strategy may well demand much more than simply the alignment of resources and market orientation. Third, can these strategies extend beyond public leisure provision? There are numerous competitive markets in which public organizations operate implying that this is likely to be true, but this inference may not hold. We advise continued research along these lines of enquiry to further enhance our understanding of what underpins successful strategies.

\section{ACKNOWLEDGEMENTS}

We are grateful to the anonymous referees for their comments and suggestions, which contributed greatly to the improvement of this article.

\section{REFERENCES}

Andrews, R., G.A. Boyne, K.J. Meier, L.J. O’Toole Jr. and R.M. Walker. 2012. 'Vertical Strategic Alignment and Public Service Performance’, Public Administration, 90, 1, 77-98. 
Andrews, R., G.A. Boyne, J. Law and R.M. Walker. 2011. 'Strategy Implementation and Public Service Performance', Administration \& Society, 43, 6, 643-671.

Andrews, R., G.A. Boyne, J. Law and R.M. Walker. 2009. 'Strategy, Structure and Process in the Public Sector: A Test of the Miles and Snow Model’, Public Administration, 87, 4, 732-749.

Andrews, R., G.A. Boyne and R.M. Walker. 2006. 'Strategy Content and Organizational Performance: An Empirical Analysis’, Public Administration Review, 66, 1, 52-63.

Benson, A.M. and S. Henderson. 2005. 'Strategic Characteristics of Sport and Recreation Provision: An Application of SPACE Analysis', Managing Leisure, 10, 4, 251-267.

Boschken, H.L. 2000. 'Behavior of Urban Public Authorities Operating in Competitive Markets Policy Outcomes in Mass Transit', Administration \& Society, 31, 6, 726-758.

Boyne, G.A. and R.M. Walker. 2004. 'Strategy Content and Public Service Organizations', Journal of Public Administration Research and Theory, 14, 2, 231-252.

Boyne, G.A. and R.M. Walker. 2010. ‘Strategic Management and Public Service Performance: The Way Ahead', Public Administration Review, 70, SI, December, S185-S192.

Brewer, G.A. and R.M. Walker. 2010. 'Explaining Variation in Perceptions of Red Tape: A Professionalism-Marketization Model', Public Administration, 88, 2, 418-438.

Bryson, J.M., F. Ackermann and C. Eden. 2007. 'Putting the Resource-Based View of Strategy and Distinctive Competencies to Work in Public Organizations’, Public Administration Review, 67, 4, 702-717.

Delaney, J.T. and M.A. Huselid. 1996. 'The Impact of Human Resource Management Practices on Perceptions of Organizational Performance', Academy of Management Journal, 39, 4, 949-969. 
DeSarbo, W.S., A.C. Di Benedetto, M. Song and I. Sinha. 2005. 'Revisiting the Miles and Snow Strategic Framework: Uncovering Interrelationships between Strategic Types, Capabilities, Environmental Uncertainty, and Firm Performance’, Strategic Management Journal, 26, 1, 47-74.

Faulkner, D. and C. Bowman. 1995. The Essence of Competitive Strategy. London: Prentice Hall.

Hodgkinson, I.R. 2013. ‘Are Generic Strategies “Fit for Purpose” in a Public Service Context?’, Public Policy and Administration, 28,1, 90-111.

Hodgkinson, I.R. and P. Hughes. 2012. 'The Performance Implications of Strategic Capital for Public Leisure Providers', Service Industries Journal, 32, 8, 1375-1391.

Hooley, G.J. and G.E. Greenley. 2005. 'The Resource Underpinnings of Competitive Positions’, Journal of Strategic Marketing, 13, 2, 93-116.

Houlihan, B. and M. Green. 2009. 'Modernization and Sport: The Reform of Sport England and UK Sport', Public Administration, 87, 3, 678-698.

Hughes, P. and R.E. Morgan. 2007. ‘A Resource-Advantage Perspective of Product-Market Strategy Performance and Strategic Capital in High Technology Firms’, Industrial Marketing Management, 36, 4, 503-517.

Hughes, P. and R.E. Morgan. 2008. 'Fitting Strategic Resources with Product-Market Strategy: Performance Implications’, Journal of Business Research, 61, 4, 323-331.

Hunt, S.D. 2000. A General Theory of Competition. Thousand Oaks: Sage.

Johanson, J. 2009. ‘Strategy Formation in Public Agencies’, Public Administration, 87, 4, 872-891.

Johnson, G., K. Scholes and R. Whittington. 2008. Exploring Corporate Strategy. Essex: Prentice Hall. 
Ketchen, D.J. and C.L. Shook. 1996. 'The Application of Cluster Analysis in Strategic Management Research', Strategic Management Journal, 17, 6, 441-458.

Kohli, A.K. and B.J. Jaworski. 1990. 'Market Orientation: The Construct, Research Propositions, and Managerial Implications', Journal of Marketing, 54, 2, 1-18.

Kohli, A.K., B.J. Jaworski and A. Kumar. 1993. ‘MARKOR: A Measure of Market Orientation’, Journal of Marketing Research, 30, 4, 467-477.

Krohmer, H., C. Homburg and J.P. Workman. 2002. 'Should Marketing be Cross-Functional? Conceptual Development and International Empirical Evidence', Journal of Business Research, 55, 6, 451-465.

Lindell, M.K. and D. J. Whitney. 2001. 'Accounting for Common Method Variance in Cross-Sectional Designs’, Journal of Applied Psychology, 86, 1, 114-121.

Liu, Y.D, P. Taylor and S. Shibli. 2008. 'Utilizing Importance Data to Identify Customer Segments for English Public Sport Facilities’, Managing Leisure, 13, 3, 189-206.

Malhotra, N.K., S.S. Kim and A. Patil. 2006. 'Common Method Variance in IS Research: A Comparison of Alternative Approaches and a Reanalysis of Past Research’, Management Science, 52, 12, 18651883.

Meier, K.J., L.J. O’Toole Jr., G.A. Boyne and R.M. Walker. 2007. ‘Strategic Management and the Performance of Public Organizations: Testing Venerable Ideas against Recent Theories’, Journal of Public Administration Research and Theory, 17, 3, 357-377.

Meier, K.J., L.J. O’Toole Jr., G.A. Boyne and R.M. Walker and R. Andrews. 2010. ‘Alignment and Results: Testing the Interaction Effects of Strategy, Structure, and Environment from Miles and Snow', Administration \& Society, 42, 2, 160-192.

Miles, R.E. and C.C. Snow. 1978. Organizational Strategy, Structure, and Process. NY: McGraw-Hill. 
Noble, C.H. and M.P. Mokwa.1999. 'Implementing Marketing Strategies: Developing and Testing a Managerial Theory', Journal of Marketing, 63, 4, 57-73.

Obeng, K. and I. Ugboro. 2008. 'Effective Strategic Planning In Public Transit Systems’, Transportation Research Part E, 44, 3, 420-439.

Porter, M.E. 1985. Competitive Advantage: Creating and Sustaining Superior Performance. NY: Macmillan Publishing.

Saunders, J.A. 1999. ‘Cluster Analysis’, in G.J. Hooley and M.K. Hussey (eds), Quantitative Methods in Marketing. London: International Thomson Business Press, pp. 41-59.

Snell, S.A. and J.W. Dean Jr. 1992. ‘Integrated Manufacturing and Human Resource Management: A Human Capital Perspective’, Academy of Management Journal, 35, 3, 467-504

Spector, P.E. and M.T. Brannick. 1995. 'The Nature and Effects of Method Variance in Organizational Research’, in C.L. Cooper and I.T. Robertson (eds), International Review of Industrial and Organizational Psychology 10. Chichester: Wiley: 249-274.

Vázquez, R., L.I. Alvarez and M.L. Santos. 2002. 'Market Orientation and Social Services in Private Non-Profit Organizations', European Journal of Marketing, 36, 10, 1022-1046.

Vining A.R. 2011. 'Public Agency External Analysis Using a Modified “Five Forces” Framework', International Public Management Journal, 14, 1, 63-105.

Walker, R.M., R. Andrews, G.A. Boyne, L.J. O’Toole Jr. and K.J. Meier. 2010. 'Wakeup Call: Strategic Management, Network Alarms and Performance', Public Administration Review, 70, 5, 731-41.

Walker, R.M., G.A. Brewer, G.A. Boyne and C.N. Avellaneda. 2011. 'Market Orientation and Public Service Performance: New Public Management Gone Mad?’, Public Administration Review, 71, 5, 707-717. 
Ward, J.H. 1963. 'Hierarchical Grouping to Optimize an Objective Function', Journal of the American Statistical Association, 58, March, 236-244. 
TABLE 1 Final cluster solution with mean values

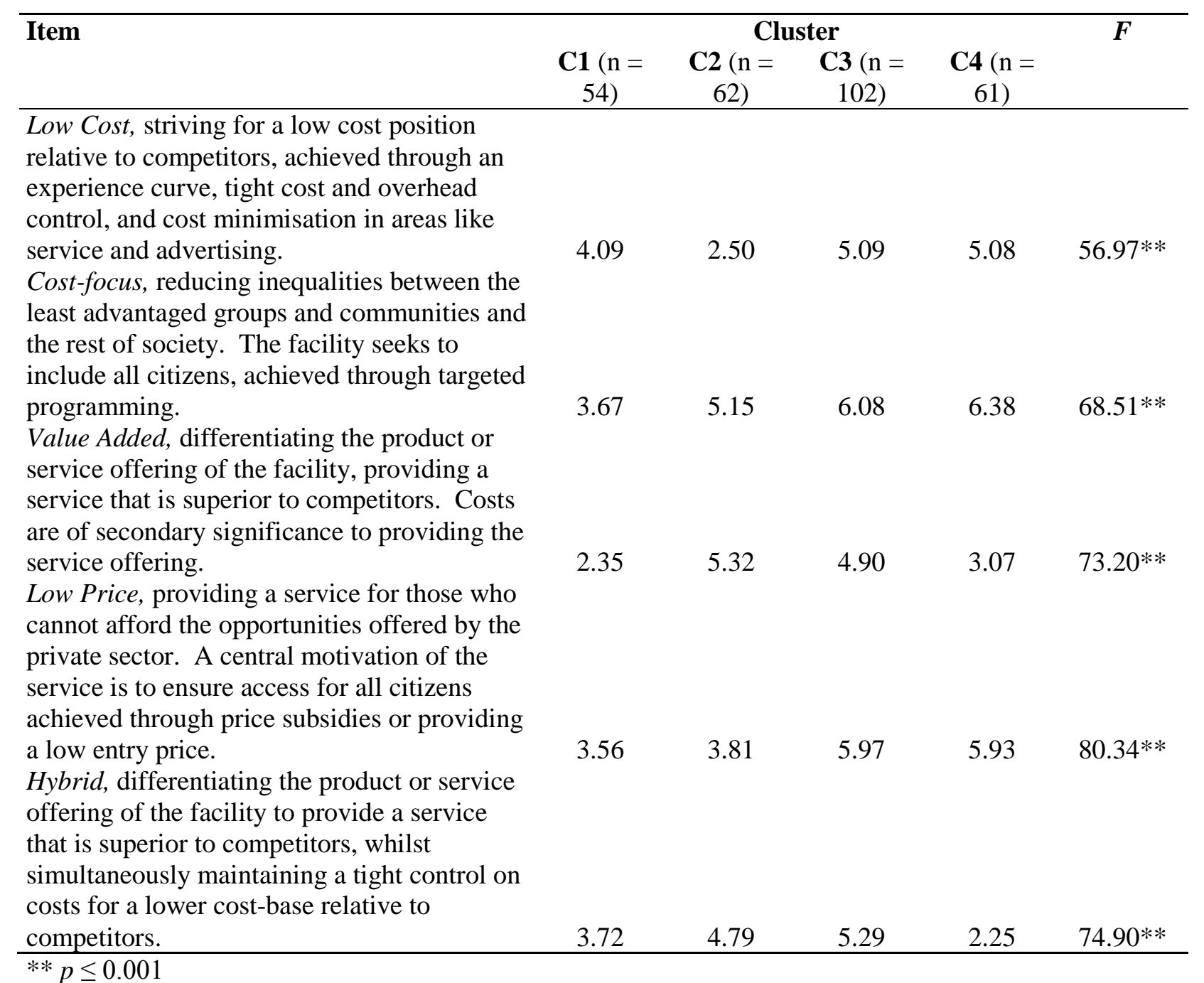


TABLE 2 Discriminant analysis

\begin{tabular}{|c|c|c|c|}
\hline \multirow[t]{2}{*}{ Item } & \multicolumn{3}{|c|}{ Standardized discriminant function coefficients } \\
\hline & $\begin{array}{c}\text { Discriminant } \\
\text { function } 1\end{array}$ & $\begin{array}{c}\text { Discriminant } \\
\text { function } 2\end{array}$ & $\begin{array}{c}\text { Discriminant } \\
\text { function } 3\end{array}$ \\
\hline Low Cost & 0.37 & -0.43 & 0.56 \\
\hline Cost-focus & 0.56 & -0.02 & -0.50 \\
\hline Value Added & 0.29 & 0.67 & -0.31 \\
\hline Low Price & 0.64 & -0.19 & 0.11 \\
\hline Hybrid & 0.22 & 0.59 & 0.66 \\
\hline Eigenvalues & 1.91 & 1.55 & 0.44 \\
\hline Cluster 1 Centroid & -2.18 & -0.78 & 0.73 \\
\hline Cluster 2 Centroid & -0.94 & 1.65 & -0.73 \\
\hline Cluster 3 Centroid & 1.37 & 0.49 & 0.50 \\
\hline Cluster 4 Centroid & 0.59 & -1.81 & -0.73 \\
\hline$\%$ of Original Group Correctly Classified & & $98 \%$ & \\
\hline
\end{tabular}


TABLE 3 Cluster differences along dimensions of strategic action

\begin{tabular}{|c|c|c|c|c|c|c|}
\hline \multirow[t]{2}{*}{ Dimension } & \multicolumn{4}{|c|}{ Cluster [group means (S.D.)] } & \multirow[t]{2}{*}{ F-ratio $^{\mathrm{a}}$} & \multirow{2}{*}{$\begin{array}{c}\text { Scheffé test } \\
(p \leq .05)\end{array}$} \\
\hline & Chaotic & $\begin{array}{c}\text { Value } \\
\text { Differentiation }\end{array}$ & Equilibrial & $\begin{array}{c}\text { Socially } \\
\text { Responsible }\end{array}$ & & \\
\hline Commitment & $4.67(1.10)$ & $5.48(1.20)$ & $5.10(1.13)$ & $4.64(1.08)$ & 7.54 & $\begin{array}{l}\mathrm{C} 1<\mathrm{C} 2 \\
\mathrm{C} 4<\mathrm{C} 2\end{array}$ \\
\hline Support & $3.82(1.43)$ & $4.67(1.35)$ & $4.39(1.34)$ & $3.93(1.41)$ & 5.10 & $\begin{array}{l}\mathrm{C} 1<\mathrm{C} 2 \\
\mathrm{C} 4<\mathrm{C} 2\end{array}$ \\
\hline Implementation & $4.20(1.30)$ & $5.11(1.22)$ & $4.86(1.17)$ & $4.13(1.41)$ & 9.23 & $\begin{array}{l}\mathrm{C} 1<\mathrm{C} 2 \\
\mathrm{C} 1<\mathrm{C} 3 \\
\mathrm{C} 4<\mathrm{C} 2 \\
\mathrm{C} 4<\mathrm{C} 3\end{array}$ \\
\hline Learning & $4.22(1.11)$ & $4.53(1.29)$ & $4.99(1.04)$ & $4.40(1.35)$ & 5.98 & $\begin{array}{l}\mathrm{C} 1<\mathrm{C} 3 \\
\mathrm{C} 4<\mathrm{C} 3\end{array}$ \\
\hline Training & $4.84(1.31)$ & $5.72(1.10)$ & $5.61(1.17)$ & $5.05(1.30)$ & 7.82 & $\begin{array}{l}\mathrm{C} 1<\mathrm{C} 2 \\
\mathrm{C} 1<\mathrm{C} 3 \\
\mathrm{C} 4<\mathrm{C} 2 \\
\mathrm{C} 4<\mathrm{C} 3\end{array}$ \\
\hline MOGeneration & $5.01(1.57)$ & $5.92(1.04)$ & $5.93(1.10)$ & $5.68(1.25)$ & 7.57 & $\begin{array}{l}\mathrm{C} 1<\mathrm{C} 2 \\
\mathrm{C} 1<\mathrm{C} 3 \\
\mathrm{C} 1<\mathrm{C} 4\end{array}$ \\
\hline MODissemination & $4.60(1.37)$ & $4.98(1.38)$ & $5.10(1.41)$ & $4.20(1.79)$ & 5.30 & $\begin{array}{l}\mathrm{C} 4<\mathrm{C} 2 \\
\mathrm{C} 4<\mathrm{C} 3\end{array}$ \\
\hline MOResponse & $5.13(1.04)$ & $5.87(0.98)$ & $5.62(0.90)$ & $5.41(1.05)$ & 6.20 & $\begin{array}{l}\mathrm{C} 1<\mathrm{C} 2 \\
\mathrm{C} 1<\mathrm{C} 3 \\
\mathrm{C} 4<\mathrm{C} 2\end{array}$ \\
\hline
\end{tabular}

${ }^{\mathrm{a}}$ F-ratios are statistically significant where $p \leq 0.001$. ${ }^{\dagger} p \leq 0.10$ 
TABLE 4 Cluster differences along dimensions of performance

\begin{tabular}{|c|c|c|c|c|c|c|}
\hline \multirow[t]{2}{*}{$\begin{array}{l}\text { Dimension } \\
\text { (im }\end{array}$} & \multicolumn{4}{|c|}{ Cluster [group means (S.D.)] } & \multirow[t]{2}{*}{$F$-ratio ${ }^{a}$} & \multirow{2}{*}{$\begin{array}{l}\text { Scheffé test } \\
(p \leq .05)\end{array}$} \\
\hline & Chaotic & $\begin{array}{c}\text { Value } \\
\text { Differentiation }\end{array}$ & Equilibrial & $\begin{array}{c}\text { Socially } \\
\text { Responsible }\end{array}$ & & \\
\hline $\begin{array}{l}\text { Customer } \\
\text { Performance }\end{array}$ & $5.00(0.92)$ & $5.60(0.91)$ & $5.41(0.90)$ & $5.12(0.91)$ & 5.42 & $\begin{array}{l}\mathrm{C} 1<\mathrm{C} 2 \\
\mathrm{C} 1<\mathrm{C} 3 \\
\mathrm{C} 4\end{array}$ \\
\hline $\begin{array}{l}\text { Business } \\
\text { Performance }\end{array}$ & $4.37(0.97)$ & $5.26(0.95)$ & $4.78(0.96)$ & $4.20(1.06)$ & 14.12 & $\begin{array}{l}\mathrm{C} 1<\mathrm{C} 2 \\
\mathrm{C} 3<\mathrm{C} 2 \\
\mathrm{C} 4<\mathrm{C} 2 \\
\mathrm{C} 4<\mathrm{C} 3\end{array}$ \\
\hline
\end{tabular}

${ }^{\mathrm{a}}$ F-ratios are statistically significant at $p \leq 0.001$.

${ }^{\dagger} p \leq 0.10$ 
APPENDIX A Measurement item properties

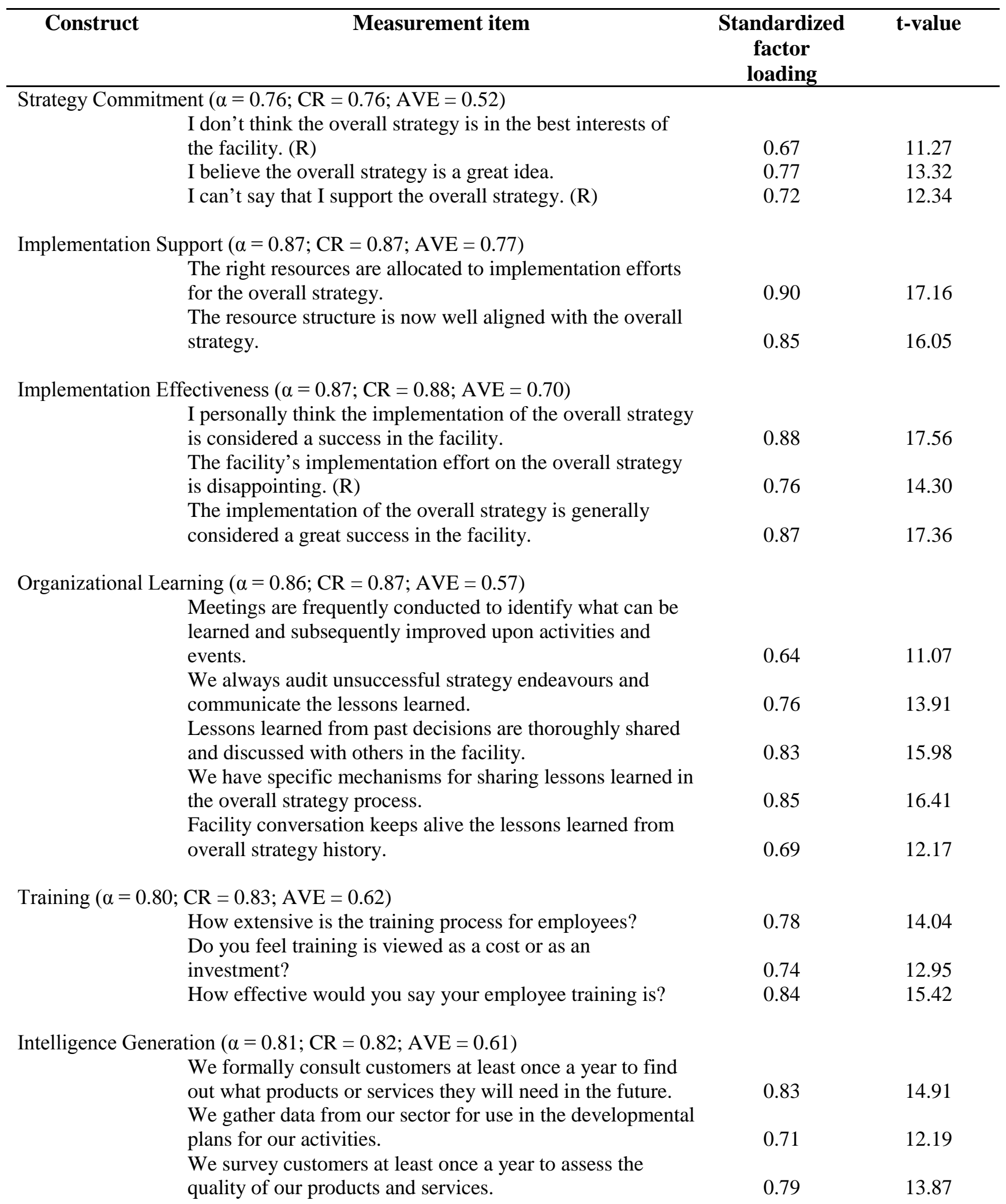

Intelligence Dissemination $(\alpha=0.60 ; \mathrm{CR}=0.61 ; \mathrm{AVE}=0.44)$ 
We have meetings at least once a quarter to discuss market trends and developments.

Our leisure facility periodically circulates documents (e.g., reports, newsletters) that provide information on our customers.

Responsiveness $(\alpha=0.70 ; \mathrm{CR}=0.61 ; \mathrm{AVE}=0.34)$

For one reason or another we tend to ignore changes in our customers' service needs. (R)

We periodically review our service development efforts to ensure that they are in line with what customers want.

Even if we came up with a great marketing plan, we probably would not be able to implement it in a timely fashion. (R)

Business Performance $(\alpha=0.82$; CR $=0.83$; AVE $=0.55)$

Attracting new customers.

Marketing.

Profitability.

Market share.

Customer Performance $(\alpha=0.81 ; \mathrm{CR}=0.83$; $\mathrm{AVE}=0.55)$

Achieving customer satisfaction.

(R) Item reverse-coded $\alpha$ Cronbach Alpha C.R. Construct reliability

AVE Average variance extracted 
APPENDIX B Strategy clusters summary

\begin{tabular}{|c|c|c|c|c|}
\hline & C1 $(n=54)$ & $C 2(n=62)$ & C3 (n = 102) & $C 4(n=61)$ \\
\hline \multirow{2}{*}{$\begin{array}{l}\text { Label } \\
\text { Description }\end{array}$} & Chaotic & Value Differentiation & Equilibrial & Socially Responsible \\
\hline & $\begin{array}{l}\text { Offerings of average } \\
\text { quality and service } \\
\text { with lower value to } \\
\text { competitors. } \\
\text { Limited dedication to } \\
\text { any service } \\
\text { objectives with no } \\
\text { clear direction. }\end{array}$ & $\begin{array}{l}\text { High attention to } \\
\text { customer needs. } \\
\text { Tailored offerings } \\
\text { through targeted } \\
\text { programming. } \\
\text { Maintains average } \\
\text { prices through cost } \\
\text { control. }\end{array}$ & $\begin{array}{l}\text { Balanced approach } \\
\text { to provision for } \\
\text { all. } \\
\text { Superior value in } \\
\text { service quality } \\
\text { alongside low } \\
\text { prices by cost } \\
\text { minimization. }\end{array}$ & $\begin{array}{l}\text { Focused on cost } \\
\text { behaviour. } \\
\text { Low price relative to } \\
\text { competitors for } \\
\text { accessibility. } \\
\text { Value is secondary } \\
\text { to lowering the } \\
\text { cost base. }\end{array}$ \\
\hline $\begin{array}{l}\text { Strategic } \\
\text { Resources }\end{array}$ & $\begin{array}{l}\text { Lowest on } \\
\text { implementation } \\
\text { support, learning, } \\
\text { and training. } \\
\text { Restricted ability to } \\
\text { develop service } \\
\text { provision for the } \\
\text { future. }\end{array}$ & $\begin{array}{l}\text { Highly committed to } \\
\text { delivering value. } \\
\text { High availability of } \\
\text { resources to invest in } \\
\text { strategy } \\
\text { implementation, } \\
\text { support and training. }\end{array}$ & $\begin{array}{l}\text { High on all resources } \\
\text { with a strong } \\
\text { learning orientation } \\
\text { necessary to modify } \\
\text { and adjust service } \\
\text { provision to meet a } \\
\text { range of objectives. }\end{array}$ & $\begin{array}{l}\text { Lowest on } \\
\text { commitment and } \\
\text { effectiveness. } \\
\text { Difficulty achieving } \\
\text { desired goals } \\
\text { despite learning } \\
\text { and training } \\
\text { efforts. }\end{array}$ \\
\hline $\begin{array}{l}\text { Market } \\
\text { Orientation }\end{array}$ & $\begin{array}{l}\text { Lowest intelligence } \\
\text { generation with an } \\
\text { inability to respond } \\
\text { to the limited } \\
\text { knowledge that is } \\
\text { disseminated. } \\
\text { Restricted adaptation } \\
\text { to customer needs. }\end{array}$ & $\begin{array}{l}\text { High knowledge } \\
\text { generation and rapid } \\
\text { response to this } \\
\text { intelligence enabling } \\
\text { quick adaptation to } \\
\text { changing customer } \\
\text { needs and delivery } \\
\text { of valued offerings. }\end{array}$ & $\begin{array}{l}\text { Collects, diffuses, } \\
\text { and responds to } \\
\text { intelligence } \\
\text { allowing } \\
\text { providers to offer } \\
\text { value to all } \\
\text { market segments } \\
\text { over time. }\end{array}$ & $\begin{array}{l}\text { Directed effort to } \\
\text { collect and } \\
\text { respond to } \\
\text { intelligence. } \\
\text { Limited effort to } \\
\text { disseminate } \\
\text { knowledge beyond } \\
\text { decision-makers. }\end{array}$ \\
\hline
\end{tabular}

